\title{
Control-Oriented Model of Molar Scavenge Oxygen Fraction for Exhaust Recirculation in Large Diesel Engines
}

Nielsen, Kræn Vodder; Blanke, Mogens; Eriksson, Lars; Vejlgaard-Laursen, Morten

Published in:

Journal of Dynamic Systems, Measurement and Control

Link to article, DOI:

$10.1115 / 1.4034750$

Publication date:

2016

Document Version

Peer reviewed version

Link back to DTU Orbit

Citation (APA):

Nielsen, K. V., Blanke, M., Eriksson, L., \& Vejlgaard-Laursen, M. (2016). Control-Oriented Model of Molar Scavenge Oxygen Fraction for Exhaust Recirculation in Large Diesel Engines. Journal of Dynamic Systems, Measurement and Control, 139(2), [021007 ]. https://doi.org/10.1115/1.4034750

\section{General rights}

Copyright and moral rights for the publications made accessible in the public portal are retained by the authors and/or other copyright owners and it is a condition of accessing publications that users recognise and abide by the legal requirements associated with these rights.

- Users may download and print one copy of any publication from the public portal for the purpose of private study or research.

- You may not further distribute the material or use it for any profit-making activity or commercial gain

- You may freely distribute the URL identifying the publication in the public portal 


\title{
Control-Oriented Model of Molar Scavenge Oxygen Fraction for Exhaust Recirculation in Large Diesel Engines
}

\author{
Kræn Vodder Nielsen ${ }^{1,2}$, Mogens Blanke ${ }^{2,4}$, Lars Eriksson ${ }^{3}$, Morten Vejlgaard-Laursen ${ }^{1}$ \\ ${ }^{1}$ MAN Diesel \& Turbo, Copenhagen, Denmark \\ 2 Automation and Control Group, Dept. of Electrical Engineering, \\ Technical University of Denmark, Kgs. Lyngby, Denmark \\ ${ }^{3}$ Vehicular Systems, Dept. of Electrical Engineering Linköping University, Linköping, Sweden \\ ${ }^{4}$ AMOS CoE, Inst. of Technical Cybernetics, Norwegian Univ. of Science and Technology, \\ Trondheim, Norway \\ e-mail: KraenV.Nielsen@man.eu,mb@elektro.dtu.dk, larer@isy.liu.se, Morten.Laursen@man.eu
}

\begin{abstract}
Exhaust gas recirculation (EGR) systems have been introduced to large marine engines in order to reduce $\mathrm{NO}_{x}$ formation. Adequate modelling for control design is one of the bottlenecks to design EGR control that also meets emission requirements during transient loading conditions. This paper therefore focus on deriving and validating a mean-value model of a large two-stroke crosshead diesel engines with EGR. The model introduces a number of amendments and extensions to previous, complex models and shows in theory and practice that a simplified nonlinear model captures all essential dynamics that is needed for EGR control. Our approach is to isolate and reduce the gas composition part of the more complex models using nonlinear model reduction techniques. The result is a control-oriented model (COM) of the oxygen fraction in the scavenge manifold with three molar flows being inputs to the COM, and it is shown how these flows are estimated from signals that are commonly available. The COM is validated by first comparing the output to a simulation of the full model, then by comparing with measurement series from two engines. The control oriented nonlinear model is shown to be able to replicate the behavior of the scavenge oxygen fraction well over the entire envelope of load and blower speed range that are relevant for EGR. The simplicity of the new model makes it suitable for observer and control design, which are essential steps to meet the emission requirements for marine diesel engines that take effect from 2016.
\end{abstract}

\section{Introduction}

Diesel engines have long been the preferred means of propulsion power production on ocean-going vessels for reasons of high fuel efficiency and reliability. Increased focus on environmental protection have introduced concern regard- ing the emissions of $\mathrm{CO}_{2}, \mathrm{SO}_{x}$ and $\mathrm{NO}_{x}$ from the marine diesel engines. $\mathrm{NO}_{x}$ emissions are subject to restriction in the Tier III standard introduced by the International Maritime Organization [1]. These regulations apply to vessels built after 1st of January 2016 when operating in specified $\mathrm{NO}_{x}$ Emission Control Areas (NECA). Currently the North American coastal area is such an NECA and the North Sea and Baltic Sea are expected to become NECAs as well [2]. A reduction of $76 \%$ is required compared to the Tier II standard. Such reduction by a factor of four is difficult to obtain and models are needed that could be used for design of robust control and estimation schemes.

Formation of $\mathrm{NO}_{x}$ in a diesel engine occurs during the combustion process where high temperatures lead to reactions between nitrogen and oxygen, known as the Zeldovich mechanism [3]. Efforts to decrease the specific fuel oil consumption (SFOC) have lead to increased peak combustion temperatures and thus $\mathrm{NO}_{x}$. Therefore a trade-off between SFOC and $\mathrm{NO}_{x}$ formation must be made in a conventional diesel engine. The severity of emission reduction specified in the Tier III regulation however, makes it infeasible to simply shift this trade-off in favor of lower emissions. New approaches are necessary in order to meet the challenge. After-treatment systems such as Selective Catalytic Reduction (SCR) remove $\mathrm{NO}_{x}$ from the exhaust gas but consume supplied chemicals in the process. Several methods exist to add water to the combustion process by e.g. emulsion into the fuel or direct injection into the combustion chamber. This circumvents the SFOC/NO $\mathrm{NO}_{x}$ trade-off by changing the gas composition of the combustion. Addition of water increases the heat capacity and decreases the availability of oxygen, resulting in lower peak temperatures while maintaining acceptable SFOC.

Exhaust gas recirculation (EGR) has a similar effect on 
heat capacity as water addition and decreases the oxygen fraction of the combustion mix more significantly. The latter affects flame formation and thus even lower peak temperatures occur. A trade-off with SFOC still exists when using EGR, but at much better terms. Choosing the right amount of recirculated gas flow is critical to obtain the best compromise. At excessively low scavenging oxygen levels the combustion is incomplete and visible smoke is produced. This effect is well known on turbocharged engines where turbolag limits the possible loading rates. Careful control of the exhaust gas recirculation is required if smoke is to be avoided when load increasing occurs, e.g. during manoeuvring.

Engine designer MAN Diesel \& Turbo has introduced high pressure EGR technology to their large two-stroke diesel engines. A simplified sketch of the gas flows in such an engine is shown in Figure 1. Gas from the exhaust receiver is cleaned and cooled in the EGR Unit before being pressurized by the EGR blower and mixed into the scavenge flow before the scavenge receiver. The flow rate of recirculated gas is controlled by varying blower speed $\omega_{e b}$ or cut-out valve opening $\alpha_{c o v}$.

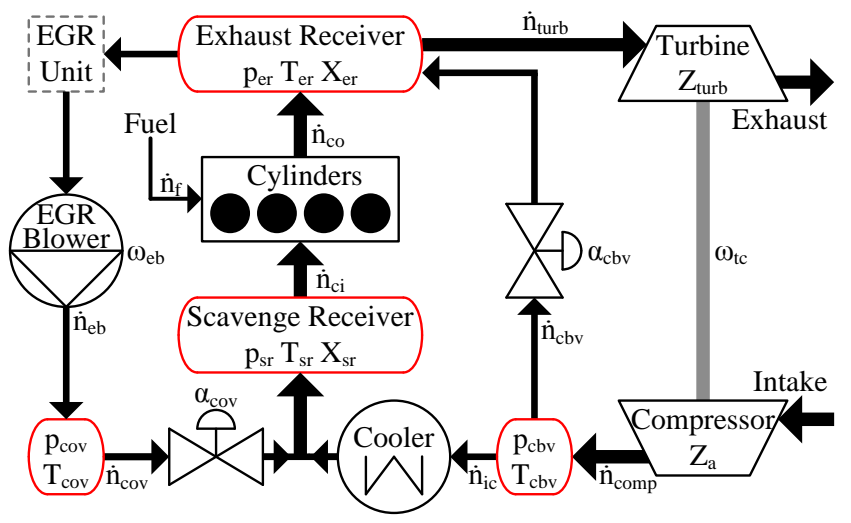

Fig. 1. Overview of main gas flows and components of the engine with exhaust gas recirculation and cylinder by-pass valve.

The correct amount of recirculated flow is implicitly decided by calculating a number of operating points in which the $\mathrm{NO}_{x}$ emission is acceptable. These points are characterized by engine load and by the partial pressure of oxygen in the scavenge receiver $\left(O_{s r}\right)$. Linear interpolation in load results in a scavenge oxygen set point for the EGR controller. An example is shown in Figure 2. Engine load is a sufficient characteristic of the operating region as engine load and speed correlates due to the propeller curve.

The existing control strategy is fixed gain proportionalintegral feedback control, which has been applied to several engine setups. During stationary running conditions the performance is adequate but it suffers in engine loading transients. In such a transient the fuel flow to the cylinders is adjusted by the governor. This affects the fraction of oxygen in the recirculated flow and thus $\mathrm{O}_{s r}$. An opposite effect comes from the change in turbocharger speed and thus fresh air flow, but this response is slower. These disturbances

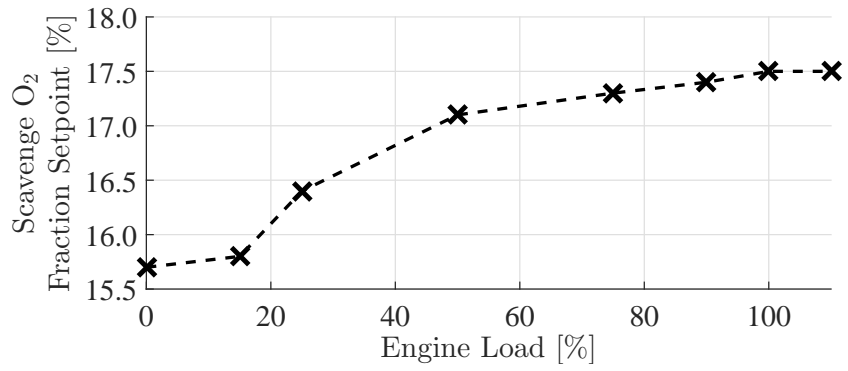

Fig. 2. An example of required scavenge oxygen fraction as a function of engine load. The linearly interpolated commissioning points are specific to the engine.

are compensated by feedback control but the slow nature of the system and difficulties in the measurement of $\mathrm{O}_{s r}$ limits the achievable performance [4]. As smoke formation must be avoided it is necessary to restrict the engine loading rate when running a fixed-gain EGR control. This is problematic considering that the Emission Control Areas cover ports and coastal areas where sufficient maneuvering capabilities are required.

In order to deal with these challenges a research effort was started that covers modeling and simulation of the airpath of large two-stroke crosshead engines with EGR, analysis of said models with respects to control properties and design of controllers based on the results. Where previous papers presented first principle simulation models, the present paper simplifies earlier models to arrive at a control-oriented model that only includes the most dominant effects of the gas composition system. This paper shows, through analytical considerations, how a low order nonlinear model can adequately describe the dominating effects. The efficacy of the model is validated by simulation, on a diesel engine at a test bed and at sea.

\subsection{Literature}

The popularity and wide-spread use of internal combustion engines have facilitated a large amount of research and published literature. An extensive treatment of engine processes and modeling was published by Heywood [3]. More recent material that also include more on control systems include Guzzella \& Onder [5] and Eriksson \& Nielsen [6]. Turbocharging issues were treated in works by Watson \& Janota [7] and more recently by Dixon [8] among others.

The large two-stroke crosshead engines, which are treated in the present paper, are less common in literature. Most relevant is the governor (engine speed controller) design that had some popularity at the end of the last century [9-12]. This incited the development of more accurate dynamic models of the engine speed behavior as function of fuel pump index. Turbocharger dynamics turned out to be an important part of these models. A discussion of various model types are found in [13]. Examples of these are found in $[14,15]$. Introduction of $\mathrm{NO}_{x}$ emission limits lead to the use of variable geometry turbines (VGT) as in [16]. Extensive treatment of marine diesel engine control was given 
in [17], that also discusses why it is challenging to provide an accurate model for such an engine. More recent investigations of large two-stroke marine diesel engine models are found in [18-22].

Due to the relative novelty and scarcity of EGR systems for large two-stroke crosshead engines only a few papers on its control properties have been found. All of them stem from the work published by Hansen et al in two papers about modeling [23] and control [4], respectively. The work on modeling was further developed by Alegret et al in [24] where the cylinder bypass valve (CBV) was introduced and estimation of model parameters was changed. A different approach to EGR control was published by the authors of the present paper in [25] based on a simple control oriented model and a nonlinear controller.

Literature on modeling and control of EGR systems is much more abundant for four-stroke automotive engines. Here the EGR system is usually accompanied by a variablegeometry turbine for faster response in transients. This naturally leads to a difficult optimisation problem with regards to control design as seen in [26-31]. The mean value model of such a system published in [32] was the inspiration of the modeling work done by Hansen et al in [23]. The effect of fuel composition on intake oxygen fraction of an automotive engine with EGR was presented in [33] and an observer design that was able to estimate said fuel composition was presented in [34]. While the published literature on automotive engines serve as inspiration to the work on large twostrokes some significant differences do apply. The very limited engine test bed availability that makes extensive parameter mapping infeasible was discussed in [17]. Furthermore the time constants of e.g. turbo-lag and gas mixing is slower, the relationship between engine speed and torque is more predictable due to the propeller curve and the heavy fuel oil creates a hostile environment for the sensors.

\subsection{Purpose}

Mean value, filling and emptying models (MVEM) are an obvious choice for simulation of the EGR system when evaluating a controller design. It allows for modular model development with first principle modeling available for most component types. These models are accurate enough for simulation of essential control properties [32]. Parameter estimation can be challenging if the sensor setup and datasets are inadequate but it is possible ( $[23,24])$.

A simple model that only represents the most dominant behavior of the system is desirable for designing a simple and effective controller. It is not intuitively obvious how to design a controller from the MVEM models due to their complexity. SISO methods based on a linearized MVEM were investigated in [4] where it was difficult to achieve both performance and robustness. A simple control-oriented model was briefly presented in [25]. The main contribution of the present paper is a slightly different version of this model along with a direct derivation from the MVEM and validation by comparison to simulation results from the MVEM and a number of measurement series from two engines.
The starting point for this paper is an MVEM based on the work presented in [24]. A brief analysis of the model structure reveals that the gas composition part of the model can be isolated. It is then simplified by removing nondominant dynamics. The result is a control-oriented model (COM) of the scavenge receiver oxygen fraction which is the essential parameter for the EGR controller. Three physical flows act as inputs to the model and it is shown how to approximate these from available sensor signals.

\subsection{Outline of this paper}

A mean-value, filling and emptying model of the EGR system is introduced in Section 2 along with a brief review of the model structure. Section 3 presents an analytical approach to reduce the complexity of the gas composition model and how to estimate inputs to the simplified model from commonly available signals. Section 4 compares the reduced model to simulations of the MVEM and measurement series from two engines, one running at a test bench, another during actual operation at sea. Symbols and abbreviations are listed in Appendix A.

\section{Mean-value engine model}

This section presents a first principle model of the engine air path. As the model is a continuation of previous work some of the origins of the model is presented along with reasons for the changes and additions in the present version. The presentation of the model itself is divided into subsections of the main components of the engine air path. The oxygen sensor is discussed in a separate subsection. The last subsection reviews couplings between the states of the model.

The purpose of the MVEM is to model the behavior of the oxygen fraction in the scavenge receiver. The main inputs of the model is engine load, EGR blower speed and the opening angle of various valves in the engine airpath.

On the current engines the EGR system can only be started when the engine is running at steady state. During the EGR start-up procedure the blower speed and COV opening are defined by a fixed sequence of a few minutes. After this, the closed loop EGR controller is used. As the MVEM is intended for control design and closed loop EGR control only occurs with an up-and-running EGR system, the model is initialized as a running system as well.

\subsection{Origin}

The engine considered is the two-stroke crosshead diesel engine designated 4T50ME-X located in MDT's Diesel Research Center in Copenhagen. The most basic parameters of the engine is provided in Table 1. The first effort to model scavenge receiver oxygen behavior when the EGR system is included was presented in [23]. This work was inspired by [18] and [32]. The result was a filling and emptying model with a mean value assumption for the flow through the cylinders. Identifiability of unknown parameters proved difficult 
due to system complexity, sensor setup and availability of suitable datasets.

Table 1. Parameters of test engine

\begin{tabular}{lll}
\hline Number of cylinders & 4 & {$[-]$} \\
Bore & 0.5 & {$[\mathrm{~m}]$} \\
Stroke & 2.2 & {$[\mathrm{~m}]$} \\
Scavenge pressure at MCR & 4.7 & {$[\mathrm{bar}]$} \\
Engine speed at MCR & 123 & {$[\mathrm{RPM}]$} \\
Effective power at MCR & 7.1 & {$[\mathrm{MW}]$} \\
\hline
\end{tabular}

Further work on this model was presented in [24]. The most notable changes were the addition of the cylinder bypass valve, advanced calculation of temperature of the flow from the cylinders and a new method of parameter estimation that included a larger number of datasets.

\subsection{Changes and additions}

The full model used in the present paper is based on [24]. Sections 2.3-2.8 describe the main points of this model, including some changes that are listed and explained below:

1. Gas composition is modelled as a vector of molar fractions instead of oxygen mass fraction only.

2. Gas flows are modelled as molar flows instead of mass flow to support the gas composition model.

3. EGR string is split in separate flow components for EGR blower and cut-out valve with a volume in between.

4. Recirculation valve is removed.

As the oxygen level in the scavenge receiver is measured in molar fraction rather than mass fraction it is more convenient to model molar fraction directly instead of converting. To support this change the gas flows are modelled as molar flows rather than mass flow. The change in gas flow modelling allows for the use of the universal gas constant in the flow component models and thus simplifies the parameters of the model. Parameters of the flow components are based on the result of the estimation carried out in [24]. An overview of the engine air path and the flows included in the model is provided in Figure 1. Models of the separate components are presented in the following sections.

\subsection{Volumes}

A filling and emptying model represents the amount of gas in a number of volumes between flow components as states. Some models also represent gas temperature in these volumes as state variables but in the present case these dynamics are neglected. This is referred to as an isothermal volume model [6]. As is common practice the amount of gas in a volume is expressed as a pressure state, by use of the ideal gas law.
Large volumes result in slower filling and emptying dynamics than smaller volumes as more gas flow is needed to change the pressure in the larger space. In a marine twostroke engine the scavenge and exhaust receivers are the largest and thus most dominant in the frequency range of EGR control. They are, however, fast compared to the dynamics of engine and turbocharger RPM and [18] argues that they can be lumped together with the turbocharger speed dynamics for model simplification.

In the present model scavenge and exhaust receiver pressures are modeled with the following differential equations

$$
\dot{p}_{s r}=\frac{R T_{s r}}{V_{s r}}\left(\dot{n}_{i c}+\dot{n}_{c o v}-\dot{n}_{c i}\right)
$$

$$
\dot{p}_{e r}=\frac{R T_{e r}}{V_{e r}}\left(\dot{n}_{c o}-\dot{n}_{e b}+\dot{n}_{c b v}-\dot{n}_{t i}\right)
$$

For model consistency it is most convenient to not connect any flow components (valves, blowers etc) in series. Therefore two small extra volumes are modeled solely to avoid this. The first is before the CBV

$$
\dot{p}_{c b v}=\frac{R T_{c b v}}{V_{c b v}}\left(\dot{n}_{c o m p}-\dot{n}_{i c}-\dot{n}_{c b v}\right)
$$

The second is before the EGR cut-out valve (COV).

$$
\dot{p}_{c o v}=\frac{R T_{c o v}}{V_{c o v}}\left(\dot{n}_{e b}-\dot{n}_{c o v}\right)
$$

\subsection{Turbocharger}

Flows and efficiencies of the compressor and turbine are calculated in the same manner as in [24], where super ellipses fitted to maps from the manufacturer are used for interand extrapolation. Parameters for the ellipses from [24] are adjusted in order to get molar rather than mass flow.

As compressor and turbine efficiencies are defined as the ratio between actual power transfer and that of an ideal adiabatic process, they facilitate calculation of temperature after the compressor as well as power transfers $P_{t u r b}$ and $P_{\text {comp }}$ to and from the rotating part of the turbocharger [6]. $P_{\text {turb }}$ and $P_{\text {comp }}$ are used in the dynamic equation of the shaft speed $\omega_{t c}$. Note that the mechanical efficiency is included in the turbine efficiency.

$$
\dot{\omega}_{t c}=\frac{P_{t u r b}-P_{c o m p}}{J_{t c} \omega_{t c}}
$$

The cylinder by-pass enters the exhaust receiver very near the turbine and the by-pass air passes directly through there without mixing into the exhaust receiver gas (see Figure 3). Therefore $T_{e r}$ is set to equal the cylinder flow temperature 
only, instead of a mix of $T_{c o}$ and $T_{c b v}$. Turbine inlet temperature $T_{t i}$ is, however, an average of $T_{e r}$ and $T_{c b v}$ weighted by the respective flows and heat capacities. The part of the turbine flow that stems from the exhaust receiver (and not the by-pass) is found as $\dot{n}_{c o}-\dot{n}_{e b}$ rather than $\dot{n}_{t u r b}-\dot{n}_{c b v}$ to avoid an algebraic loop between the calculations of $T_{t i}$ and $\dot{n}_{t u r b}$.

$$
T_{t i}=\frac{\left(\dot{n}_{c o}-\dot{n}_{e b}\right) c_{p, e r} T_{e r}+\dot{n}_{c b v} c_{p, a m b} T_{c b v}}{\left(\dot{n}_{c o}-\dot{n}_{e b}\right) c_{p, e r}+\dot{n}_{c b v} c_{p, a m b}}
$$

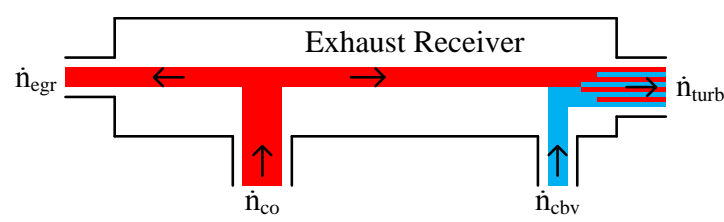

Fig. 3. The cylinder by-pass (CBV) flow mixes directly into the turbine flow and not the exhaust receiver.

\subsection{EGR Blower}

Molar flow through the EGR blower is calculated by assuming a relationship between the non-dimensional parameters head coefficient $(\Psi)$ and flow coefficient $(\Phi)$.

$$
\Phi=a\left(1-\left(\frac{\Psi}{b}\right)^{n}\right)^{\frac{1}{n}}
$$

where

$$
\Psi=2 c_{p, e b} T_{e b} \cdot \frac{\Pi_{e b}^{\frac{\gamma-1}{\gamma}}}{\omega_{e b}^{2} r^{2}} \quad, \quad \Phi=\frac{\dot{n}_{e b} R T_{e b}}{\omega p_{e b} \pi r^{3}}
$$

The temperature in the EGR string is assumed to be constant due to the EGR cooler (part of the EGR Unit) .

\subsection{Valves and Cooler}

All valves are modeled as compressible turbulent restrictions with variable openings [6].

$$
\dot{n}_{v}=\frac{A(\alpha) p_{\text {in }}}{\sqrt{R T_{\text {in }}}} \sqrt{\frac{2 \gamma}{\gamma-1}\left(\left(\frac{p_{\text {out }}}{p_{\text {in }}}\right)^{\frac{2}{\gamma}}-\left(\frac{p_{\text {out }}}{p_{\text {in }}}\right)^{\frac{\gamma+1}{\gamma}}\right)}
$$

The cooler is modeled as an incompressible turbulent restriction.

$$
\dot{n}_{i c}=A_{i c} \sqrt{\frac{p_{c b v}}{R T_{c b v}}\left(p_{c b v}-p_{s r}\right)}
$$

Scavenge receiver temperature $T_{s r}$ is assumed to be constant due to the effectiveness of the cooler.

\subsection{Cylinders}

A mean value approach is used for the flow $\left(\dot{n}_{c i}\right)$ from the scavenge receiver through the cylinders to the exhaust receiver. The cylinders are modeled as a compressible turbulent restriction (Eq. 9) but with a fixed opening. The total flow $\dot{n}_{c o}$ from cylinder to exhaust receiver is larger than $\dot{n}_{c i}$ due to the addition of and reaction with fuel. As in [24] we assume a lean combustion reaction. Here on the form

$$
\mathrm{CH}_{y}+\left(1+\frac{y}{4}\right) \mathrm{O}_{2} \rightarrow \mathrm{CO}_{2}+\frac{y}{2} \mathrm{H}_{2} \mathrm{O}
$$

where the virtual fuel molecule $\mathrm{CH}_{y}$ is introduced to simplify the analysis. The fuel constant $y$ refers to the total ratio of hydrogen to carbon among the different species in the fuel. As an example isooctane $\mathrm{C}_{8} \mathrm{H}_{18}$ corresponds to a fuel with $y=18 / 8=2.25$, and the molar flow of the virtual fuel $\mathrm{CH}_{2.25}$ is 8 times that of $\mathrm{C}_{8} \mathrm{H}_{18}$. For every 1 virtual fuel molecule, $1+\frac{y}{4}$ oxygen molecules are converted to 1 carbon-dioxide and $\frac{y}{2}$ water molecules. Thus if $\dot{n}_{f}$ denotes the molar flow of $\mathrm{CH}_{y}$ the total flow from cylinder to exhaust receiver is

$$
\dot{n}_{c o}=\dot{n}_{c i}+\left(-1-\frac{y}{4}+1+\frac{y}{2}\right) \dot{n}_{f}=\dot{n}_{c i}+\frac{y}{4} \dot{n}_{f}
$$

The temperature of flow from cylinders to exhaust receiver is calculated from a modified limited pressure diesel cycle. A detailed explanation is found in [24].

\subsection{Gas composition}

Scavenge gas composition is the essential variable for the EGR controller and thus also essential to the model. In [23] and [24] oxygen mass fraction of the scavenge and exhaust receivers, respectively, were modeled. In the present paper the molar fraction is used to better relate to the scavenge oxygen sensor signal. Also the two oxygen fraction states are expanded to vectors of gas composition states that includes fractions of both $\mathrm{O}_{2}, \mathrm{CO}_{2}$ and $\mathrm{H}_{2} \mathrm{O}$. The remaining part of the gas is assumed to be $\mathrm{N}_{2}$. As the total amount of gas is described by the pressure state (along with temperature and volume) an explicit $\mathrm{N}_{2}$ state would be redundant. The gas composition vector of the gas in receiver $i$ is defined as

$$
X_{i}=\frac{\left[\begin{array}{lll}
n_{i, O_{2}} & n_{i, \mathrm{CO}_{2}} & n_{i, H_{2} O}
\end{array}\right]^{T}}{n_{i, \text { total }}}
$$

The gas composition vector of a flow at position $j$ is defined as

$$
Z_{j}=\frac{\left[\begin{array}{lll}
\dot{n}_{j, O_{2}} & \dot{n}_{j, \mathrm{CO}_{2}} & \dot{n}_{j, \mathrm{H}_{2} O}{ }^{T}
\end{array}\right]^{T}}{\dot{n}_{j, \text { total }}}
$$

The differential equations for the gas composition in the scavenge and exhaust receivers, respectively, are

$$
\dot{X}_{s r}=\frac{\dot{n}_{c o v}}{n_{s r}}\left(Z_{c o v}-X_{s r}\right)+\frac{\dot{n}_{i c}}{n_{s r}}\left(Z_{i c}-X_{s r}\right)
$$




$$
\dot{X}_{e r}=\frac{\dot{n}_{c o}}{n_{e r}}\left(Z_{c o}-X_{e r}\right)
$$

where $n_{s r}$ and $n_{e r}$ are calculated from the pressure states, temperatures and the ideal gas law. The composition $Z_{i c}$ of the cooler flow equals that of ambient air $X_{a}$.

The composition $Z_{c o}$ of the flow out of the cylinders is based on $\dot{n}_{c i}$ (with composition $Z_{c i}=X_{s r}$ ) and the effect of the fuel

$$
Z_{c o}=\frac{\dot{n}_{c i} X_{s r}+\dot{n}_{f} \Gamma}{\dot{n}_{c o}} \quad, \quad \Gamma=\left[\begin{array}{c}
-1-\frac{y}{4} \\
1 \\
\frac{y}{2}
\end{array}\right]
$$

where $\Gamma$ is a constant vector that relates to the combustion reaction.

Assuming that the gas composition of the recirculated gas does not change in the EGR unit and that the volume between EGR blower and COV is small enough to be neglected for the composition dynamics leads to

$$
Z_{\text {cov }}=X_{e r}
$$

Using this and equations 12 and 17 we can rewrite equations 15 and 16 as

$$
\begin{gathered}
\dot{X}_{s r}=\frac{\dot{n}_{c o v}}{n_{s r}}\left(X_{e r}-X_{s r}\right)+\frac{\dot{n}_{i c}}{n_{s r}}\left(X_{a}-X_{s r}\right) \\
\dot{X}_{e r}=\frac{\dot{n}_{c i}}{n_{e r}}\left(X_{s r}-X_{e r}\right)+\frac{\dot{n}_{f}}{n_{e r}}\left(\Gamma-\frac{y}{4} X_{e r}\right)
\end{gathered}
$$

It is possible to include sulfur content in the fuel by using the virtual fuel molecule $\mathrm{CH}_{y} \mathrm{~S}_{z}$ instead and extending the combustion reaction and the composition vectors to include $\mathrm{SO}_{2}$. Composition changes in the EGR unit (sulfur removal and humidity changes) can be included by changing the assumption expressed by Equation 18. For clarity reasons these extensions have not been included here.

\subsection{Oxygen sensor}

$\mathrm{A} \mathrm{ZrO}_{2}$ type sensor measures the molar oxygen fraction in the scavenge receiver. The pressure, temperature and gas composition is not ideal for such a sensor so in order to increase accuracy and decrease sensor wear a rather complex gas extraction system has been designed by MDT. The resulting dynamic properties of this sensor setup is difficult to model accurately. Good results have been obtained by modeling it as a time delay and a first order filtering effect

$$
\tau_{F b} \cdot \dot{O}_{s r, F b}(t)=O_{s r}\left(t-\Delta t_{F b}\right)-O_{s r, F b}(t)
$$

where $O_{s r}$ is the actual oxygen fraction, $O_{s r, F b}$ is the measurement, $\tau_{F b}$ is the sensor time constant and $\Delta t_{F b}$ is the sensor time delay. The values of $\tau_{F b}$ and $\Delta t_{F b}$ are both expected to lie in the range 10-20 seconds depending on level of clogging in the gas extraction system and pressure conditions in the receiver.

\subsection{MVEM validation}

The MVEM is validated in [24] and found to represent the main system behavior. The changes and additions in the present paper is regarded as technicalities (e.g. mass/molar) that does not affect the overall model validity. The extension of the gas composition model to include $\mathrm{CO}_{2}, \mathrm{H}_{2} \mathrm{O}$ and $\mathrm{N}_{2}$ is difficult to validate as only the $\mathrm{O}_{2}$ fraction is measured. Therefore the MVEM model is not further validated here. The reduced version is, however, validated against both the MVEM and two engines in a later section.

A disadvantage of the MVEM model is that it was parameterized and validated against data where the engine was running at the upper half of the load region. The problematic fast loading transients mainly occur at the lower half. While the overall model structure is valid at low loads the extrapolation accuracy in some of the flow components is unknown.

\subsection{Model structure}

The MVEM has 11 states of which 4 are pressures, 1 is the turbocharger speed and the remaining 6 are gas composition. The pressure and TC speed states are coupled through the flow elements as shown in Figure 4. These states affect the gas composition states whereas the gas composition states only affect the pressures and TC speed through gas property changes, an effect that is negligible in this regard. The MVEM can therefore be separated into two cascaded systems as shown in Figure 4 where the pressure, flow and TC speed part provides inputs to the gas composition part of the model.

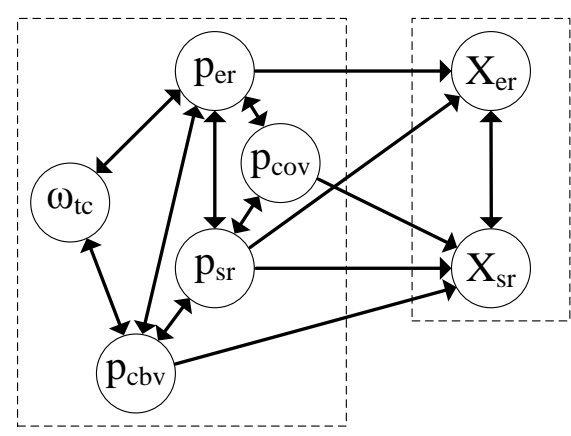

Fig. 4. A digraph shows the couplings between states in the MVEM model. The model can be separated in two cascaded systems as the gas composition states only affect each other.

\section{Control-oriented Model}

The COM is a dynamic model of the scavenge oxygen level that is simpler than the standard MVEM. The MVEM is used as a starting point, but only the gas composition part 
is considered. This section shows how to simplify the model by removing dynamics that is not essential for the gas composition and how to estimate the inputs.

\subsection{Model Reduction}

Reduction of the gas composition part can be achieved by removal of non-essential dynamics. A complete state decoupling by diagonalization is difficult due to the system nonlinearity, but a fast mode can be decoupled by triangularization of the system matrix. Simulation of the MVEM model shows that a few terms can be neglected, allowing us to rewrite the remainder of the model into a simple form with first order dynamics.

First the gas composition model is written in the form of a time-varying state space model

$$
\left[\begin{array}{c}
\dot{X}_{s r} \\
\dot{X}_{e r}
\end{array}\right]=\left[\begin{array}{cc}
-\frac{\dot{n}_{c o v}+\dot{n}_{i c}}{n_{s r}} & \frac{\dot{n}_{c o v}}{n_{s r}} \\
\frac{\dot{n}_{c i}}{n_{e r}} & -\frac{\dot{n}_{c i}+\frac{y}{4} \dot{n}_{f}}{n_{e r}}
\end{array}\right]\left[\begin{array}{c}
X_{s r} \\
X_{e r}
\end{array}\right]+\left[\begin{array}{c}
\frac{\dot{n}_{i c}}{n_{s r}} X_{a} \\
\frac{n_{f}}{n_{e r}} \Gamma
\end{array}\right]
$$

or equivalently

$$
\dot{X}=A(U) X+K(U)
$$

where

$$
\begin{gathered}
U=\left[\begin{array}{c}
\frac{\dot{n}_{c o v}+\dot{n}_{i c}}{n_{s r}} \\
\frac{\dot{n}_{c o v}}{n_{s r}} \\
\frac{\dot{n}_{c i}+\frac{y}{4} \dot{n}_{f}}{n_{e r}} \\
\frac{\dot{n}_{c i}}{n_{e r}}
\end{array}\right]=\left[\begin{array}{l}
U_{1} \\
U_{2} \\
U_{3} \\
U_{4}
\end{array}\right], \\
A(U)=\left[\begin{array}{cc}
-U_{1} & U_{2} \\
U_{4} & -U_{3}
\end{array}\right] \quad, \quad K(U)=\left[\begin{array}{c}
\left(U_{1}-U_{2}\right) X_{a} \\
\left(U_{3}-U_{4}\right) \frac{4}{y} \Gamma
\end{array}\right]
\end{gathered}
$$

If $U$ were assumed to be constant, the model in equation 23 could be separated into decoupled states by a state transformation

$$
\tilde{X}=\left[\begin{array}{l}
\tilde{X}_{1} \\
\tilde{X}_{2}
\end{array}\right] \quad, \quad X=E \tilde{X} \quad, \quad \tilde{X}=E^{-1} X
$$

where the transformation matrix $\mathrm{E}$ is chosen as the gathered eigenvectors of $\mathrm{A}$. This transformation results in a diagonal system matrix $E^{-1} A E$ so the system is split into two decoupled states. In the present case $U$ is the system input and cannot be assumed to be constant. The transformed system matrix becomes $E^{-1}(A E-\dot{E})$ which is not generally diagonal. It is, however, possible to design the transformation matrix in a way that makes $A$ triangular, thus decoupling part of the system. Choose

$$
E=E(U)=\left[\begin{array}{cc}
\frac{U_{2}}{\lambda_{1}+U_{1}} & \frac{U_{2}}{\lambda_{2}+U_{1}} \\
1 & 1+\psi(t)
\end{array}\right]
$$

where the eigenvalues of $A$ are

$$
\lambda_{1}=\lambda_{1}(U)=-\frac{U_{1}+U_{3}+\sqrt{\left(U_{1}-U_{3}\right)^{2}+4 U_{2} U_{4}}}{2}
$$

$$
\lambda_{2}=\lambda_{2}(U)=-\frac{U_{1}+U_{3}-\sqrt{\left(U_{1}-U_{3}\right)^{2}+4 U_{2} U_{4}}}{2}
$$

and $\psi(t)$ is an auxiliary state that behaves according to

$$
\dot{\psi}=-\psi^{2}\left(\lambda_{2}+U_{1}\right)-\psi\left(2 \lambda_{2}+U_{3}+U_{1}+U_{5}\right)-U_{5}
$$

$U_{5}$ is defined by the relative change of $U$ and $\lambda_{2}$

$$
U_{5}=\frac{\dot{\lambda}_{2}+\dot{U}_{1}}{\lambda_{2}+U_{1}}-\frac{\dot{U}_{2}}{U_{2}}
$$

Now the transformed system can be written on the form

$$
\left[\begin{array}{c}
\dot{\tilde{X}}_{1} \\
\dot{\tilde{X}}_{2}
\end{array}\right]=\left[\begin{array}{cc}
\tilde{a}_{11} & 0 \\
\tilde{a}_{21} & \tilde{a}_{22}
\end{array}\right]\left[\begin{array}{c}
\tilde{X}_{1} \\
\tilde{X}_{2}
\end{array}\right]+E^{-1} K
$$

where the terms $\tilde{a}_{i i}$ are time-varying. The triangular form of the system matrix is a salient feature of the model in 32 as the zero in the $\tilde{a}_{12}$ position shows that in the transformed system model, the state $\tilde{X}_{1}$ is not affected by changes in $\tilde{X}_{2}$.

The reduction now proceeds with the help of the MVEM model. Wide range simulations where $U$ is varied at realistic rates show that the auxiliary state $\psi$ remains small enough to be negligible (Figure 5), considering the form of the equations where it appears. The difference between $\tilde{a}_{11}$ and $\lambda_{1}$ is also negligible and both varies in the range $[-1 ;-0.5]$. This corresponds to a mode of the system with a time constant $\tau_{1}=\frac{1}{-\lambda_{1}}$ varying in the range 1-2 seconds which is faster than the desired range of the model (Figure 6). To simplify

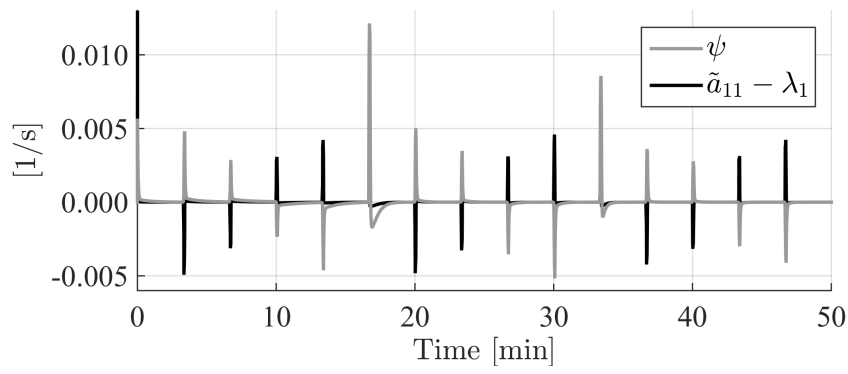

Fig. 5. The figure shows the magnitude of the terms $\psi$ and $\tilde{a}_{11}-$ $\lambda_{1}$. Both terms remain close to 0 during a simulation of the MVEM in a wide range of engine loads and EGR blower speeds with realistic input rates and they can therefore be neglected in the model.

the model these dynamics are neglected and removed. The 
removal is achieved by setting $\dot{\tilde{X}}_{1}=0$ and solving for $\tilde{X}_{1}$ in Equation 32.

$$
\tilde{X}_{1}=-\frac{\left(U_{1}-U_{2}\right) X_{a}-\frac{U_{2}}{\lambda_{2}+U_{1}}\left(U_{3}-U_{4}\right) \frac{4}{y} \Gamma}{U_{2}\left(\frac{1}{\lambda_{1}+U_{1}}-\frac{1}{\lambda_{2}+U_{1}}\right) \lambda_{1}}
$$

From the transformation in Equation 26 we can express $\tilde{X}_{1}$ in terms of the original states

$$
\tilde{X}_{1}=\frac{(1+\psi) X_{s r}-\frac{U_{2}}{\lambda_{2}+U_{1}} X_{e r}}{U_{2}\left(\frac{1+\psi}{\lambda_{1}+U_{1}}-\frac{1}{\lambda_{2}+U_{1}}\right)}
$$

Combining Equations 33 and 34 while neglecting $\psi$ we can solve for $X_{e r}$ in terms of $\mathrm{U}$ and $X_{s r}$.

$$
X_{e r}=\left(X_{s r}+\frac{K_{1}-\frac{U_{2}}{\lambda_{2}+U_{1}} K_{2}}{\lambda_{1}}\right) \frac{\lambda_{2}+U_{1}}{U_{2}}
$$

Using this result in Equation 22 with the definition of $U$ and

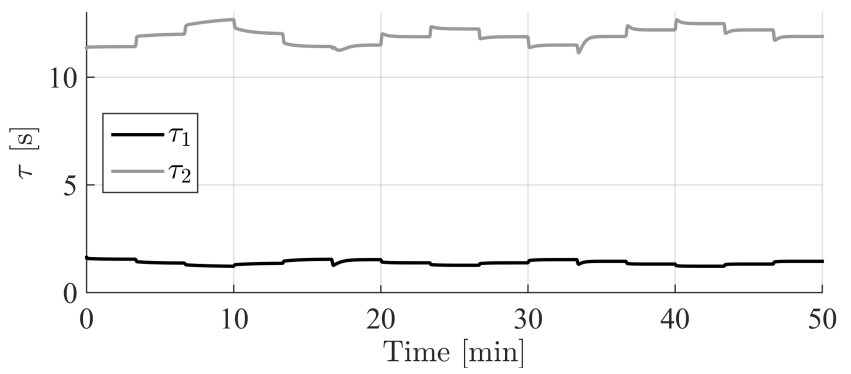

Fig. 6. Time constants $\tau_{1}$ and $\tau_{2}$ of the gas mixing process vary slightly during simulation over a wide engine load and EGR flow range.

rewriting leads to

$$
\tau_{2} \dot{X}_{s r}=-X_{s}+\frac{X_{a}\left(\dot{n}_{c i}+\frac{y}{4} \dot{n}_{f}\right) \dot{n}_{i c}+\Gamma \dot{n}_{c o v} \dot{n}_{f}}{\left(\dot{n}_{c o v}+\dot{n}_{i c}\right)\left(\dot{n}_{c i}+\frac{y}{4} \dot{n}_{f}\right)-\dot{n}_{c o v} \dot{n}_{c i}}
$$

where $\tau_{2}=\frac{1}{-\lambda_{2}}$. Simulations show $\tau_{2}$ to vary in the range 1113 seconds, depending on engine load and EGR flow (Figure 6 ). Equation 36 with a constant $\tau_{2}=12$ seconds is a reasonable model of $X_{s r}$. Further simplification can be achieved by neglecting the filling and emptying dynamics of the scavenge receiver, by setting

$$
\dot{n}_{c i}=\dot{n}_{c o v}+\dot{n}_{i c}
$$

which leads to

$$
\tau_{2} \dot{X}_{s r}=-X_{s r}+X_{a}+\frac{\left(\Gamma-X_{a} \frac{y}{4}\right) \dot{n}_{f} \dot{n}_{c o v}}{\left(\dot{n}_{i c}+\frac{y}{4} \dot{n}_{f}\right)\left(\dot{n}_{i c}+\dot{n}_{c o v}\right)}
$$

Equation 38 represents the behavour of $X_{s r}$ with only the most dominating dynamics included. One fast mode stemming from the coupling of the two receivers is removed as well as the filling and emptying dynamics of the scavenge receiver. Steady state output is maintained. The final model has the form of three parallel first order Hammerstein models where fuel, EGR and intercooler flows act as inputs. The only parameters are ambient air composition, ratio of hydrogen to carbon atoms in the fuel and a time constant.

\subsection{Input approximation}

Having developed a simple model of the gas composition dynamics we now turn to the inputs of this model. The composition $Z_{a}$ of the ambient air flow and the fuel composition ratio $y$ can be considered as known constant parameters, whereas the three gas flows $\dot{n}_{f}, \dot{n}_{c o v}$ and $\dot{n}_{i c}$ need to be estimated from signals that are available to the controller if the $\mathrm{COM}$ is to be used in an engine control system. The final setup can be seen in Figure 7.

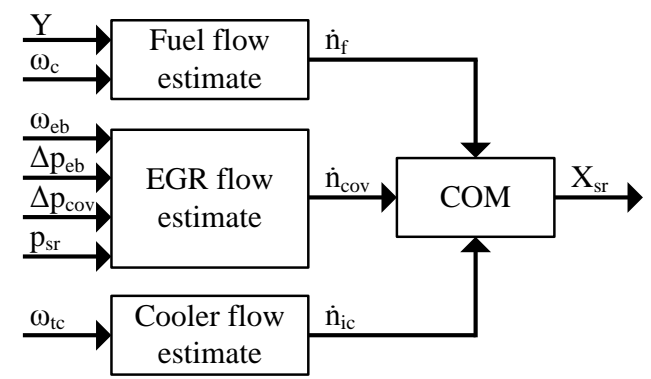

Fig. 7. Overview of the control-oriented model with its input estimates and the signals used.

\subsubsection{Fuel Flow}

The fuel flow is a control input from the governor and it can be calculated as proportional to the product of engine speed $\omega_{c}$ and governor index $Y$ with reasonable accuracy.

$$
\dot{n}_{f}=k_{f} \omega_{c} Y
$$

The constant of proportionality $k_{f}$ can be found from engine shop test data where a fuel flow measurement is available.

\subsubsection{COV Flow}

The cut-out valve is modeled as a compressible turbulent restriction with variable opening in the MVEM. Equation 9 could theoretically provide a simple way to estimate the flow. In practice, however, the COV is fully open during normal operation and does not provide enough restriction to induce a significant pressure difference. This is obviously a design choice in order to avoid counteracting the EGR blower. Speaking of which, the EGR blower provides the preferred alternative for EGR flow estimation (Equations 
7 and 8). Output pressure is calculated as scavenge pressure plus pressure difference over the COV. Input pressure is then found using the differential pressure over the blower. EGR flow temperature is assumed constant $T_{\text {egr }}=300 \mathrm{~K}$. The relation between $\Psi$ and $\Phi$ is parameterized using data made available from the blower manufacturer.

\subsubsection{Cooler Flow}

In the MVEM model the cooler is modeled as an incompressible turbulent restriction. Equation 10 should be adequate for flow estimation. Unfortunately the pressure difference over the cooler is not a commonly available signal. Also, the restriction provided by the cooler might be too small to provide adequate signal to noise ratio of the estimate. As an alternative the cooler flow can be estimated as the difference between compressor and CBV flows. However, the MVEM models for these flows require even more pressure signals as well as temperatures and a compressor flow map.

As a consequence we resort to a more crude estimation of the cooler flow inspired by the model used in [15]. Here it was argued that the compressor operates very close to a single line on a compressor map with almost constant efficiency. This facilitates modeling of the compressor flow as a simple function of $\omega_{t c}$ or $p_{s r}$ only, even during transients. Such a model was applied to an engine with neither EGR nor CBV. These additions each add an additional degree of freedom to the system and might degrade performance of the simple flow estimate.

The accuracy of this simple model as well as the effect of introducing EGR and CBV is investigated by simulation of the MVEM. Figure 8 shows $\dot{n}_{i c}$ as a function of $\omega_{t c}$ when keeping the CBV opening constant and varying either the engine load (43-100\%) or the EGR blower speed (within the relevant range). Figure 8 also shows an estimate on the form

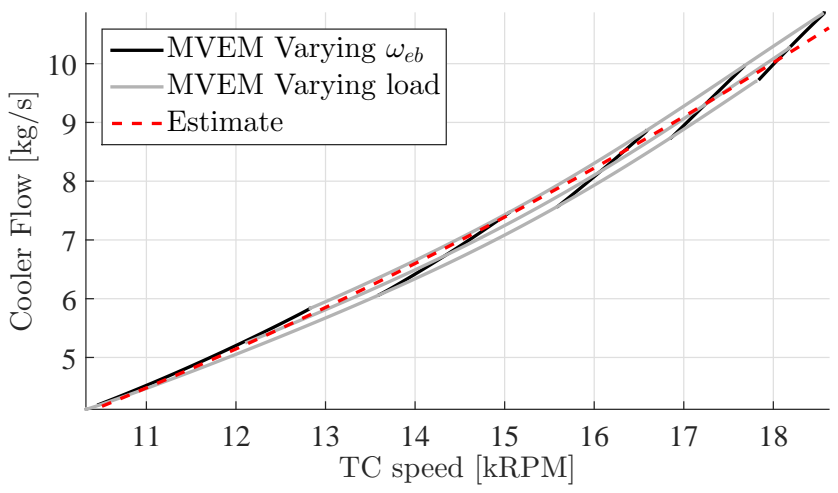

Fig. 8. Simulation and estimation of cooler flow $\dot{n}_{i c}$ with constant CBV opening and varying engine load (43-100\%) and EGR blower speed. where $\theta$ and $\phi$ are constants. The simulations show that variation of the EGR flow only slightly degrades the accuracy of the flow estimate. Problems arise when varying the CBV opening as seen in Figure 9. Clearly, the cooler flow is not well described as a function of only $\omega_{t c}$ in this case. We do not pursue to improve the estimation method here but only state that it works poorly when varying the CBV opening. Future research might solve this issue, but for now it is not deemed critical as the CBV is closed in the low engine load region where rapid load transients occur during maneuvering. The MVEM model is parameterized for the high load region where the $\mathrm{CBV}$ is normally open and therefore the investigation has been included here.

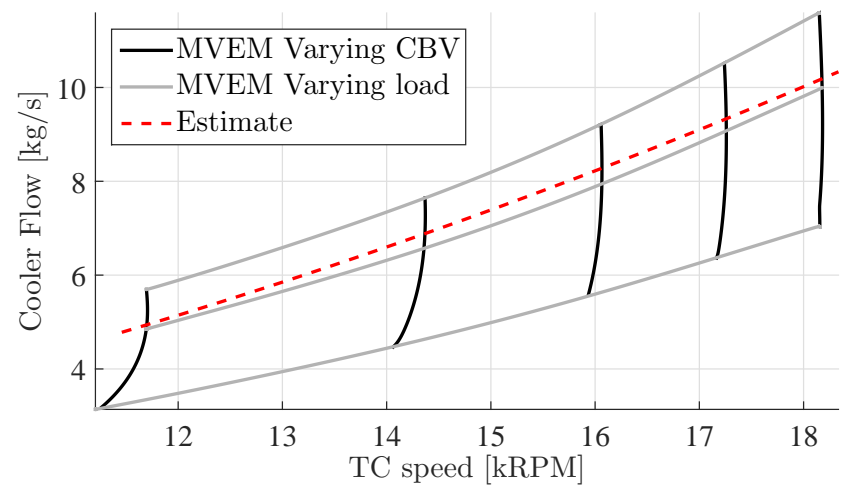

Fig. 9. Simulation and estimation of cooler flow $\dot{n}_{i c}$ with constant EGR blower speed opening and varying engine load (43-100\%) and CBV opening (0-100\%).

The dominating dynamics for the cooler flow is due to the turbocharger inertia. This is naturally captured by basing the flow estimate on $\omega_{t c}$. Figure 10 show a comparison between MVEM and Equation 40 in a scenario where engine load and EGR blower speed are changed in steps. The estimate replicates the MVEM well in transients and only seems to deviate slightly in steady state.

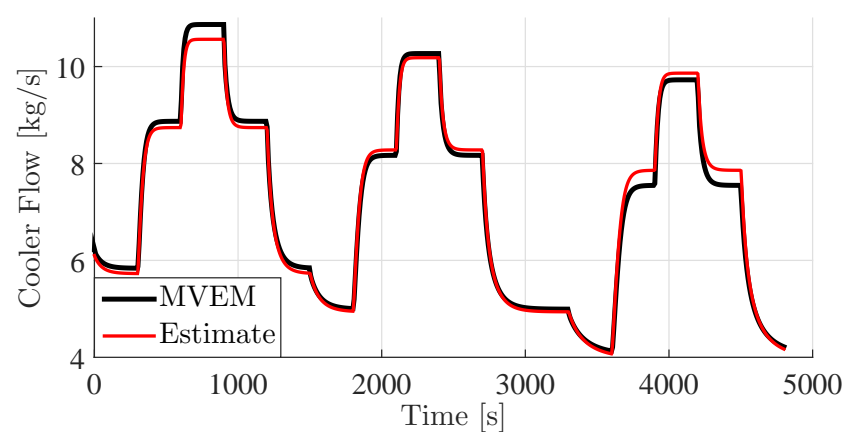

Fig. 10. Simulation and estimation of cooler flow while changing engine load (43-69-100\%) and EGR blower speed in steps.

$$
\dot{n}_{i c}=\theta \cdot\left((1-\phi) \omega_{t c}+\phi \omega_{t c}^{2}\right)
$$




\subsection{Operating region}

Equation 38 is valid throughout the load region, as long as the combustion is lean. Regarding the input approximation, the fuel flow estimate is valid globally. The provided EGR blower maps can be extrapolated to the conditions present at low load. The cooler flow estimate is unable to represent variation of the $\mathrm{CBV}$ opening. As the $\mathrm{CBV}$ is always fully closed at low loads, the consequence of this deficiency is limited with regards to EGR controller synthesis when the aim is to design a controller that is able to deal with fast loading transients, which mainly occur at low loads. On the other hand, the cooler flow estimate is subjected to extrapolation into the low load region and possible disturbance from the auxiliary blowers (not shown) which increase scavenge pressure and flow in the low load region. Comparison to experimental data (Section 4) shows the model to be robust against this.

\section{Validation of control-oriented model}

In this section the control-oriented model is validated by comparing the output to a simulation of the full MVEM model and measurement data from two engines. In the latter cases the dynamics of the scavenge oxygen sensor naturally influence the results. This is compensated by increasing the time constant in the COM and adding a time delay.

\subsection{Comparison of COM and MVEM}

The MVEM model allows us to verify the consequences of the simplifications done to the model. Matlab Simulink is used for simulation of the MVEM. Dynamic simulation of pressure in volumes that are small relative to the flows can be difficult for the solver, but Simulink's implicit ode15s solver is able to simulate the MVEM at more than 200x real time on a standard PC.

Figure 11 shows a comparison of the scavenge oxygen level simulated by the full MVEM and the COM, respectively. The scenarios are EGR blower speed steps at three different engine loads. It can be seen that the removal of fast dynamics in gas mixing and removal of filling and emptying dynamics of the scavenge receiver has almost no consequence for the accuracy. The most significant decrease in accuracy comes from the simplification of compressor flow estimation which has an influence on the steady state accuracy but does not change the dynamics significantly. Figure 12 shows a similar comparison but this time the blower speed is kept constant while the engine load is changed in steps (between 43,69 and 100\%). Here the dynamics differ slightly due to neglection of scavenge receiver filling and emptying. This effect is most evident during a load change, where the scavenge pressure changes. Deviation due to the cooler flow model is also seen at certain steady state points.

\subsection{Comparison of COM and Test Engine}

To further validate the control-oriented model it is applied to data recorded from two engines. The first is the 4T50ME-X test engine situated in the MDT Diesel Research
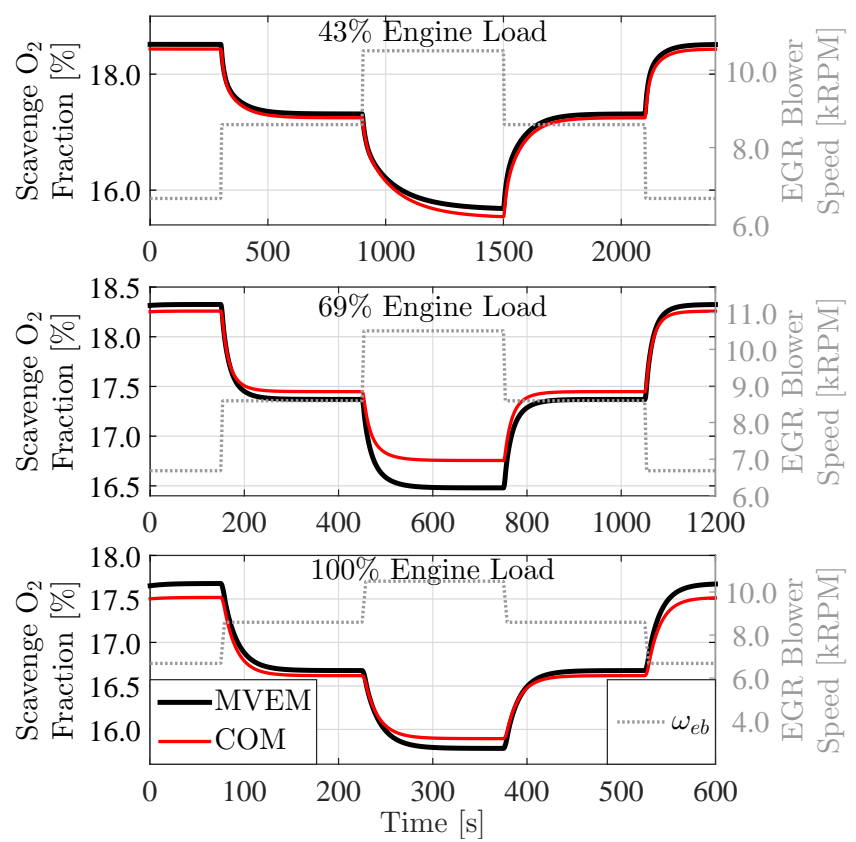

Fig. 11. Comparison of $O_{s r}$ simulated by MVEM and COM during steps of EGR blower speed at engine loads 43, 69 and $100 \%$.

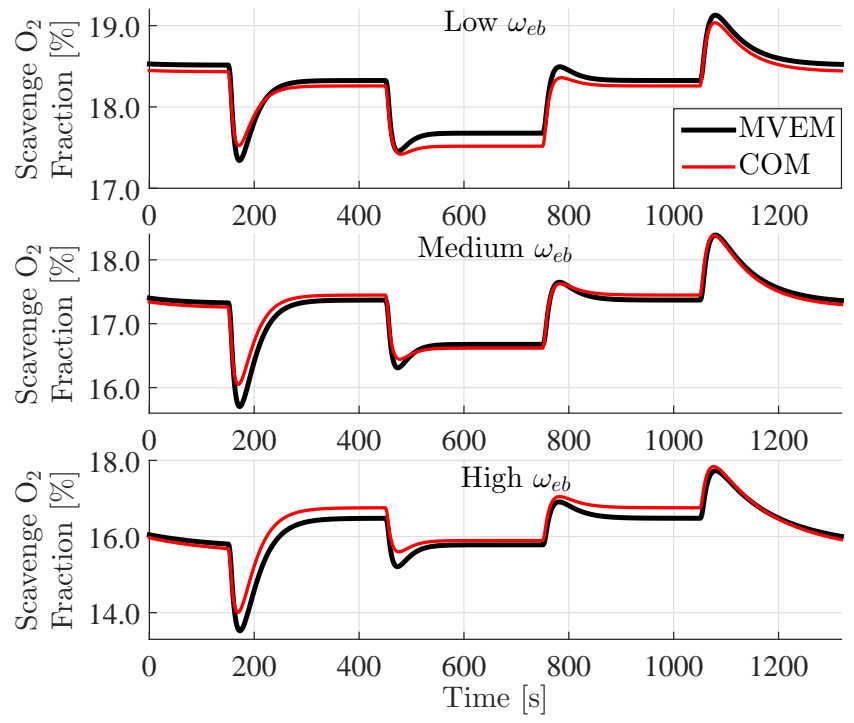

Fig. 12. Comparison of $O_{s r}$ simulated by MVEM and COM during steps of engine load (43-69-100-69-43\%) at different EGR blower speeds.

Center in Copenhagen. The oxygen sensor dynamics are incorporated by increasing the model time constant and adding a 10 second time delay. Here the first scenarios are also EGR blower speed steps at constant load (50,75 and 100\%), see Figure 13. The COM captures both the dynamics and steady state well over this wide load range. At 100\% load the COM seems to have a slight lag. This indicates that the sensor delay is shorter than 10 seconds at this load.

Figure 14 shows the COM applied to a number of engine RPM setpoint ramps in the low load range. Here the auxiliary blowers are activated but the model is able to replicate the 

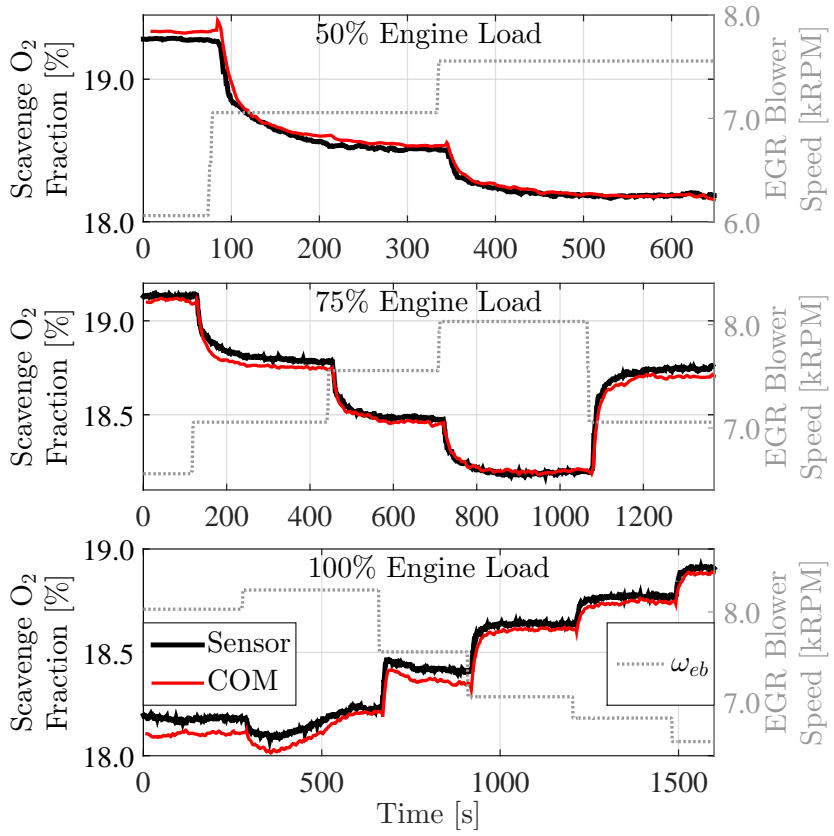

Fig. 13. Comparison of $O_{s r}$ measured on test engine and estimated by COM during steps of EGR blower speed at engine loads 50,75 and $100 \%$.

$O_{s r}$ behavior anyway.
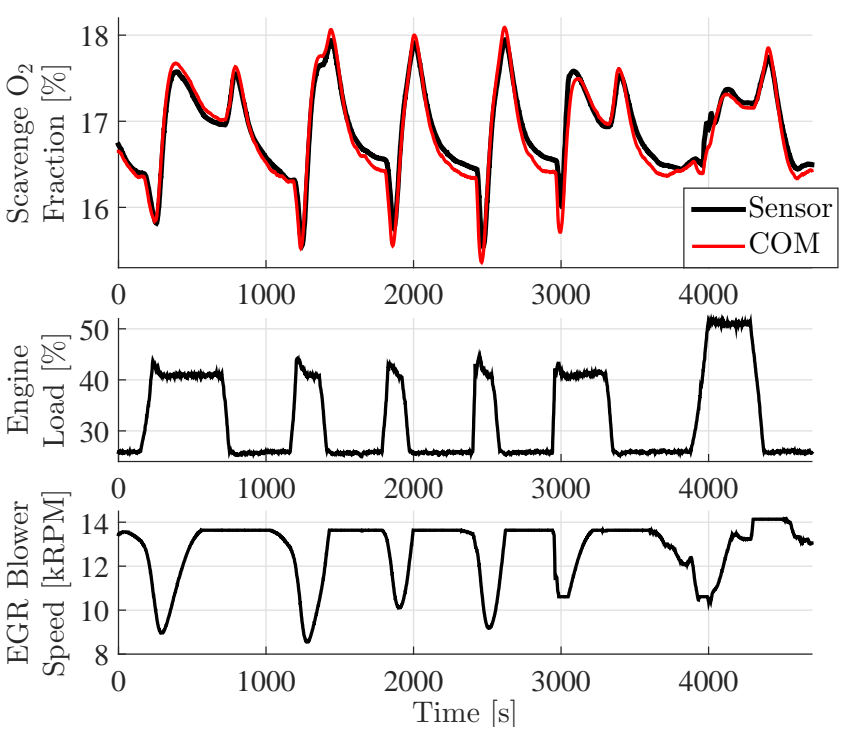

Fig. 14. Comparison of $O_{s r}$ measured on test engine and estimated by COM during a series of engine RPM setpoint changes.

\subsection{Comparison of COM and Vessel Engine}

The MVEM and the COM are models of the 4T50ME-X test engine. In order to validate the generality of the model, it is also applied to the 6S80ME-C9.2 engine installed on the container vessel Maersk Cardiff. The most basic parameters of the vessel engine is provided in Table 2. A similar scenario as previously is shown in Figure 15 where the EGR blower speed is varied stepwise in different load ranges. However, as this is from a vessel the governor does not keep a constant load and especially at the higher load ranges it is seen to affect $O_{s r}$ significantly. The COM is able to replicate the $O_{s r}$ behavior as it takes advantage of the load signal. Again the sensor delay seems to be slightly smaller than estimated at $80 \%$ load.

Table 2. Parameters of vessel engine

\begin{tabular}{lll}
\hline Number of cylinders & 6 & {$[-]$} \\
Bore & 0.8 & {$[\mathrm{~m}]$} \\
Stroke & 3.45 & {$[\mathrm{~m}]$} \\
Scavenge pressure at MCR & 3.0 & {$[\mathrm{bar}]$} \\
Engine speed at MCR & 73.9 & {$[\mathrm{RPM}]$} \\
Effective power at MCR & 23.0 & {$[\mathrm{MW}]$} \\
\hline
\end{tabular}
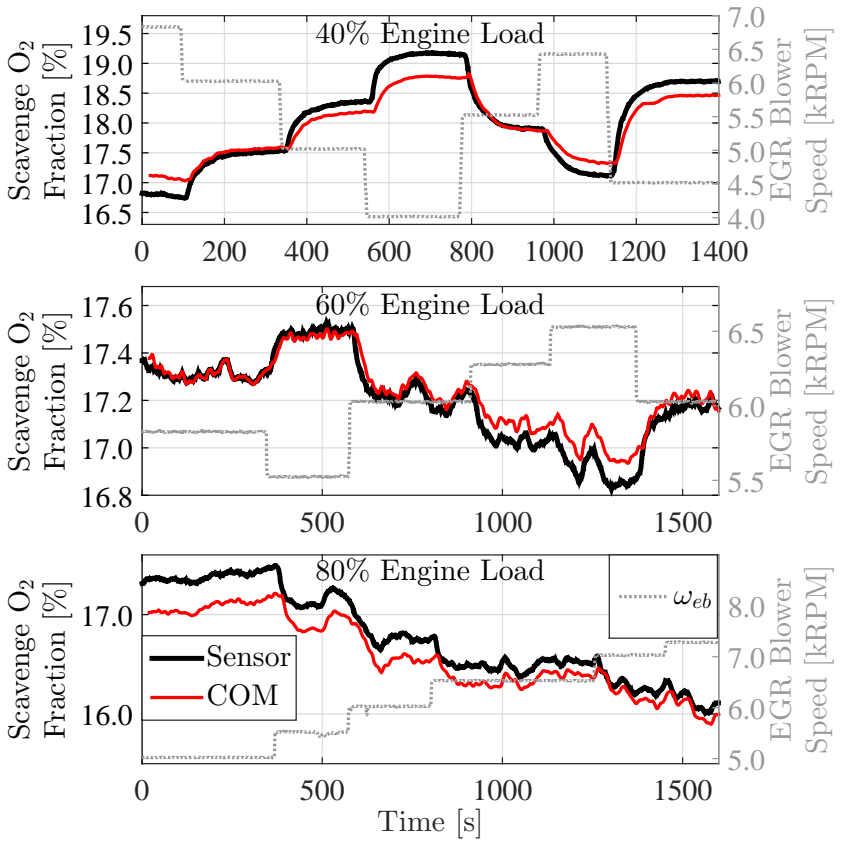

Fig. 15. Comparison of $O_{s r}$ measured on vessel engine and estimated by COM during steps of EGR blower speed at engine loads 40,60 and $80 \%$.

Figure 16 shows the COM applied to a number of RPM setpoint steps in the low load range on the vessel engine. Most of the $O_{s}$ behavior is replicated but the COM deviates somewhat from the steady state values of the sensor. 

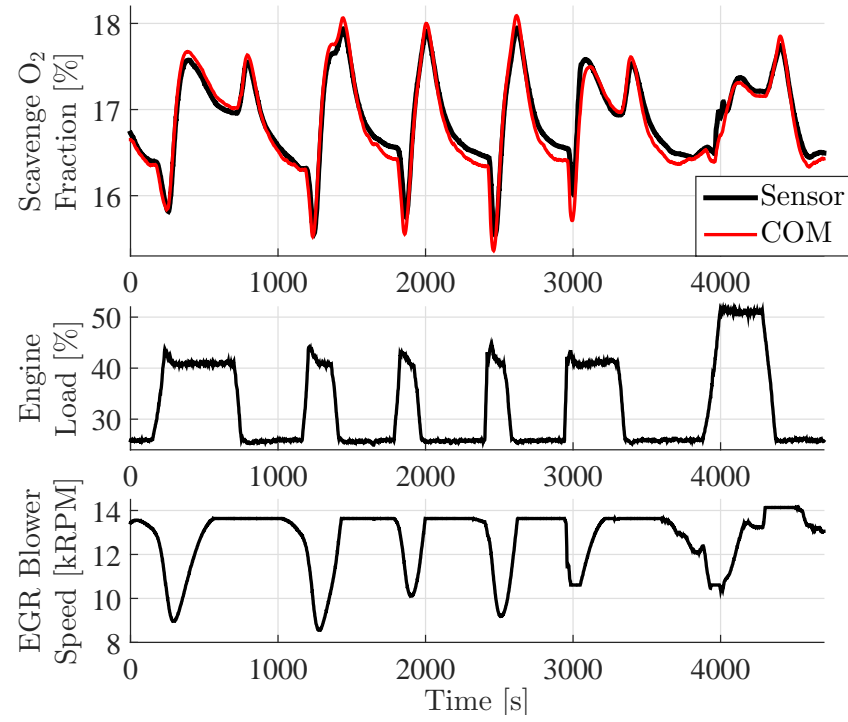

Fig. 16. Comparison of $O_{s r}$ measured on vessel engine and estimated by COM during a series of engine RPM setpoint changes.

\section{Conclusions}

This paper presented a mean value molar model of scavenge oxygen fraction in large two-stroke crosshead diesel engines with Exhaust Gas Recirculation (EGR). The purpose of the model was simulation and design of EGR closed loop control for steady state as well as transient loading conditions. The paper showed in theory and practice that our simplified nonlinear model captures all essential dynamics that is needed for EGR control.

The nonlinear control-oriented model of the molar oxygen fraction in the scavenge receiver was developed by model reduction of the gas composition part of a mean value model. Model reduction was done by transforming the system to disclose non-dominant dynamics and perform model reduction to leave the steady state response untouched. The resulting model consisted of three parallel first order Hammerstein systems with inputs being fuel flow, EGR flow and intercooler flow, and it was shown how these quantities were estimated from commonly available signals.

The performance of the control-oriented model was validated by comparison to the output of a complete MVEM model, to measurement series from a test engine and to recordings from a vessel engine in various scenarios. The model was found to capture the gas mixing dynamics well and was able to replicate the steady state response convincingly in the relevant range of operation.

The control-oriented model presented here was employed for successful observer and controller designs, which will be published separately.

\section{References}

[1] International Maritime Organization, 2013. Marpol ANNEX VI and NTC 2008, 2013: With Guidelines for Implementation.

[2] HELCOM, 2016. Workshop in russia advances neca for ships in baltic and north seas.
http://www.helcom.fi/news/Pages/Workshop-inRussia-advances-NECA-for-ships-in-Baltic-andNorth-Seas.aspx.

[3] Heywood, J. B., 1988. Internal combustion engine fundamentals. McGraw-Hill.

[4] Hansen, J. M., Blanke, M., Niemann, H. H., and Vejlgaard-Laursen, M., 2013. "Exhaust gas recirculation control for large diesel engines - achievable performance with siso design". IFAC-PapersOnLine, Elsevier Science, 46(33), pp. 346-351. IFAC Proceedings Volumes.

[5] Guzzella, L., and Onder, C. H., 2010. Introduction to modeling and control of internal combustion engine systems. Springer-Verlag.

[6] Eriksson, L., and Nielsen, L., 2014. Modeling and control of engines and drivelines. Wiley.

[7] Watson, N., and Janota, M. S., 1982. Turbocharging the Internal Combustion Engine. Macmillan.

[8] Dixon, S. L., and Hall, C. A., 2014. Fluid mechanics and thermodynamics of turbomachinery. Elsevier.

[9] Blanke, M., 1986. "Requirements of adaptive techniques for enhanced control of large diesel engines". In Proc. IFAC Workshop on Adaptive Control and Signal Processing. Lund, Sweden, IFAC, pp. 197-202.

[10] Blanke, M., and Nielsen, P. B., 1990. "The marine engine governor". In Proc. 2nd International Conf. on Maritime Communications and Control, Society of Marine Engineers, pp. 11-20.

[11] Winterbone, D. E., and Jai-In, S., 1991. "The application of modern control theory to a turbocharged diesel engine powerplant". Proceedings of the Institution of Mechanical Engineers, Part I: Journal of Systems and Control Engineering, 205(19), pp. 69-83.

[12] Banning, R., Johnson, M. A., and Grimble, M. J., 1997. "Advanced control design for marine diesel engine propulsion systems". ASME Journal of Dynamic Systems, Measurement and Control, 119(2), pp. 167174.

[13] Woodward, J. B., and Latorre, R. G., 1985. "Modeling of diesel engine transient behavior in marine propulsion analysis.". Transactions - Society of Naval Architects and Marine Engineers, 92, pp. 33-49.

[14] Blanke, M., and Andersen, J. A., 1984. "On modelling large two stroke diesel engines: New results from identification". In Proc. IFAC World Congress, Pergamon Press, pp. 2015-2020.

[15] Hendricks, E., 1986. "Compact, comprehensive model of large turbocharged, two-stroke diesel engines.". SAE Technical Paper Series.

[16] Stefanopoulou, A., and Smith, R., 2000. "Maneuverability and smoke emission constraints in marine diesel propulsion". Control Engineering Practice, 8(9), pp. 1023-1031.

[17] Xiros, N., 2002. Robust Control of Diesel Ship Propulsion. Springer London.

[18] Theotokatos, G., 2010. "On the cycle mean value modelling of a large two-stroke marine diesel engine". 
Proceedings of the Institution of Mechanical Engineers Part M: Journal of Engineering for the Maritime Environment, 224(3), pp. 193-205.

[19] Baldi, F., Andersson, K., and Theotokatos, G., 2015. "Development of a combined mean value-zero dimensional model and application for a large marine fourstroke diesel engine simulation". Applied Energy, 154, pp. 402-415.

[20] Guan, C., Theotokatos, G., and Zhou, P., 2014. "Computational investigation of a large containership propulsion engine operation at slow steaming conditions". Applied Energy, 130, pp. 370-383.

[21] Guan, C., Theotokatos, G., and Chen, H., 2015. "Analysis of two stroke marine diesel engine operation including turbocharger cut-out by using a zerodimensional model". Energies, 8(6), pp. 5738-5764.

[22] Theotokatos, G., and Tzelepis, V., 2015. "A computational study on the performance and emission parameters mapping of a ship propulsion system". Proceedings of the Institution of Mechanical Engineers Part M: Journal of Engineering for the Maritime Environment, 229(1), pp. 58-76.

[23] Hansen, J. M., Zander, C., Pedersen, N., Blanke, M., and Vejlgaard-Laursen, M., 2013. "Modelling for control of exhaust gas recirculation on large diesel engines". IFAC-PapersOnLine, Elsevier Science, 46(33), pp. 380-385. IFAC Proceedings Volumes.

[24] Alegret, G., Llamas, X., Vejlgaard-Laursen, M., and Eriksson, L., 2015. "Modeling of a large marine twostroke diesel engine with cylinder bypass valve and egr system". IFAC-PapersOnLine Elsevier Science, 48(16), pp. 273 - 278. 10th IFAC MCMC, 2015 Copenhagen.

[25] Nielsen, K. V., Blanke, M., and Vejlgaard-Laursen, M., 2015. "Nonlinear adaptive control of exhaust gas recirculation for large diesel engines". IFAC-PapersOnLine, Elsevier Science, 48(16), pp. 254 - 260. 10th IFAC Conf. on Manoeuvring and Control of Marine Craft, MCMC 2015 Copenhagen.

[26] van Nieuwstadt, M. J., Kolmanovsky, I. V., Moraal, P. E., Stefanopoulou, A., and Jankovic, M., 2000. "Egrvgt control schemes: Experimental comparison for a high-speed diesel engine". IEEE Control Systems Magazine, 20(3), pp. 63-79.

[27] Wahlström, J., and Eriksson, L., 2011. "Nonlinear EGR and VGT control with integral action for diesel engines". Oil \& Gas Science and Technology - Rev. IFP, 66(4), pp. 573-586.

[28] Wahlström, J., Eriksson, L., and Nielsen, L., 2010. "Egr-vgt control and tuning for pumping work minimization and emission control". IEEE Transactions on Control Systems Technology, 18(4), pp. 993-1003.

[29] Wahlström, J., and Eriksson, L., 2013. "Output selection and its implications for mpc of egr and vgt in diesel engines". IEEE Transactions on Control Systems Technology, 21(3), pp. 932-940.

[30] Wang, H., Tian, Y., Bosche, J., and El Hajjaji, A., 2014. "Modeling and dynamical feedback control of a vehicle diesel engine speed and air-path". Journal of Dynamic Systems Measurement and Control-transactions of the Asme, 136(6), p. 061010.

[31] Huang, M., Zaseck, K., Butts, K., and Kolmanovsky, I., 2016. "Rate-based model predictive controller for diesel engine air path: Design and experimental evaluation”. IEEE Transactions on Control Systems Technology.

[32] Wahlström, J., and Eriksson, L., 2011. "Modelling diesel engines with a variable-geometry turbocharger and exhaust gas recirculation by optimization of model parameters for capturing non-linear system dynamics". Proceedings of the Institution of Mechanical Engineers, Part D, Journal of Automobile Engineering, 225(7), pp. 960-986.

[33] Zhao, J., and Wang, J., 2013. "Effect of exhaust gas recirculation on biodiesel blend level estimation in diesel engines". Journal of Dynamic Systems, Measurement and Control-transactions of the Asme, 135(1), p. 011010.

[34] Zhao, J., and Wang, J., 2015. "Adaptive observer for joint estimation of oxygen fractions and blend level in biodiesel fueled engines". IEEE Transactions on Control Systems Technology, 23(1), pp. 80-90. 
A Nomenclature

This appendix specifies the abbreviations, lists the notation and explains subscripts used in the paper.

Table 3. Abbreviations

\begin{tabular}{ll}
\hline$C B V$ & Cylinder by-pass valve \\
$C O M$ & Control-oriented model \\
$C O V$ & Cut-out valve \\
$E G R$ & Exhaust gas recirculation \\
$M D T$ & MAN Diesel \& Turbo \\
$M C R$ & Maximum continuous rating \\
$M V E M$ & Mean-value engine model \\
NECA & NO ${ }_{x}$ Emission control area \\
$S F O C$ & Specific fuel oil consumption \\
$S C R$ & Selective catalytic reduction \\
$T C$ & Turbocharger \\
$V G T$ & Variable geometry turbine \\
\hline
\end{tabular}

Table 4. Subscripts

\begin{tabular}{ll||ll}
\hline$a$ & ambient air & $f$ & fuel \\
$c$ & crankshaft & $F b$ & feedback \\
$c b v$ & cylinder by-pass valve & $i c$ & intercooler \\
$c i$ & cylinder inlet & $s r$ & scavenge receiver \\
$c o$ & cylinder outlet & $t u r b$ & turbine \\
comp & compressor & $t i$ & turbine inlet \\
$c o v$ & cut-out valve & $t c$ & turbocharger \\
$e b$ & EGR blower & $v$ & valve \\
$e r$ & exhaust receiver & & \\
\hline
\end{tabular}

Table 5. List of symbols

$\tilde{a}$

A Area or system matrix

$c_{p} \quad$ Specific heat for constant pressure

$J \quad$ Moment of inertia

$k \quad$ Constant

$K \quad$ Constant vector

$n \quad$ Amount of moles

$\dot{n} \quad$ Molar flow

$p \quad$ Pressure

$P \quad$ Power

$R \quad$ Universal Gas Constant

$T$ Temperature

$U \quad$ Input vector

$V \quad$ Volume

$X \quad$ Molar gas fraction vector

$y \quad$ Ratio of $\mathrm{H}$ to $\mathrm{C}$ atoms in fuel

$Y \quad$ Fuel index

$Z \quad$ Molar gas fraction vector

$\alpha \quad$ Valve opening angle

$\gamma \quad$ Ratio of specific heats

$\Gamma \quad$ Combustion reaction constant

$\Delta p \quad$ Pressure difference

$\Delta t \quad$ Time delay

$\theta \quad$ Constant

$\lambda \quad$ Eigenvalue of $\mathrm{A}$

$\Pi$ Pressure ratio

$\tau$ Oxygen mixing time constant

$\phi \quad$ Constant

$\Phi \quad$ Flow coefficient

$\psi \quad$ Auxiliary state

$\Psi \quad$ Head coefficient

$\omega \quad$ Rotational speed
$[-]$

$[-]$

$[\mathrm{J} /(\mathrm{mole} \cdot \mathrm{K})]$

$\left[\mathrm{kg} \cdot \mathrm{m}^{2}\right]$

$[-]$

$[-]$

[moles]

[moles/s]

$[\mathrm{Pa}]$

[W]

$[\mathrm{J} /($ mole $\cdot \mathrm{K})]$

[K]

$[-]$

$\left[\mathrm{m}^{3}\right]$

[-]

[-]

[\%]

[-]

[\%]

[-]

[-]

$[\mathrm{Pa}]$

$[\mathrm{s}]$

[moles/rad]

[1/s]

[-]

[s]

[-]

[-]

[-]

[-]

$[\mathrm{rad} / \mathrm{s}]$ 